\title{
VARIABILIDADE GENÉTICA DE ISOLADOS DO COMPLEXO Colletotrichum ASSO- CIADOS A SEMENTES DE ALGODOEIRO, POR MEIO DE TECNICAS MOLECULARES E INOCULAÇÃO EM PLANTAS *
}

\author{
RENATA SILVA-MANN ${ }^{1}$, KALINKA C.C. SALGADO ${ }^{1}$, MARIA G.G.C. VIEIRA ${ }^{1} \&$ JOSÉ C. MACHADO $^{2}$ \\ ${ }^{1}$ Laboratório de Análise de Sementes-DAG/UFLA, e-mail: semente@ufla.br; ${ }^{2}$ Laboratório de Patologia de Sementes-DFS/ \\ UFLA, Cx. Postal 37, CEP 372000-000, Lavras, MG.
}

(Aceito para publicação em 08/10/2001)

Autor para correspondência: Maria G.G.C. Vieira

SILVA-MANN, R., SALGADO, K.C.C., VIEIRA, M.G.G.C. \& MACHADO, J.C. Variabilidade genética de isolados do complexo Colletotrichum associados a sementes de algodoeiro, por meio de técnicas moleculares e inoculação em plantas. Fitopatologia Brasileira 27:027-032. 2002.

\section{RESUMO}

A antracnose e a ramulose são doenças do algodoeiro (Gossypium hirsutum) causadas, respectivamente, por Colletotrichum gossypii e C. gossypii var. cephalosporioides, sendo a ramulose a mais importante sob o ponto de vista de prejuízos causados. Por se tratarem de fungos transmitidos por sementes, de difícil diferenciação por métodos convencionais, o desenvolvimento de metodologia usando técnicas moleculares é uma opção que se dispõe na busca de maior precisão e rapidez. O presente trabalho objetivou associar informações do teste de patogenicidade com marcadores bioquímicos e moleculares de DNA/RAPD, visando a identificação e diferenciação do complexo Colletotrichum. Foram usados dez isolados, sendo três classificados como causadores de antracnose e sete de ramulose, pelo teste de patogenicidade. Os marcadores bioquímicos não se mostraram eficientes para a distinção dos isolados causadores da ramulose e da antracnose. $\mathrm{Na}$ análise de RAPD, o valor de similaridade encontrado para os dois grupos foi de $51,7 \%$, confirmando a potencialidade da técnica para diferenciar tais fungos.

Palavras-chave adicionais: Colletotrichum gossypii, Colletotrichum gossypii var. cephalosporioides, RAPD, isoenzimas, similaridade.

\section{ABSTRACT \\ Genetic variability of Colletotrichum complex associated with cotton seeds, by using molecular markers and plant inoculation}

Anthracnosis and ramulosis are important diseases of cotton (Gossypium hirsutum), caused by Colletotrichum gossypii and $C$. gossypii var. cephalosporioides, respectively; both fungi seed transmitted. Ramulosis, also known as witch's broom, is considered to be more devastating, causing severe losses in several regions of Brazil where cotton is cultivated in large scale. It is difficult to detect both fungi in seed samples by conventional methods since the morphological variability between isolates within the same species makes detec- tion unreliable. The goal of the presente work was to investigate the variation of 10 isolates of both fungi using DNA/RAPD markers. Part of the isolates was classified as C. gossypii and part as C. gossypii var. cephalosporioides, using the pathogenic test. The results showed that the biochemical markers used were not able to distinguish the isolates of anthracnosis from the isolates of ramulosis. On the other hand, the genetic similarity between the isolates demonstrated by RAPD analysis, was $51,78 \%$, indicating the potential of this technique.

\section{INTRODUÇÃO}

O aspecto de sanidade de sementes, do ponto de vista de prognóstico e controle de doenças em plantas, tem assumido uma posição de destaque mundial, devido ao acentuado número de patógenos que podem ser transmitidos pelas sementes.

Para a cultura do algodoeiro (Gossypium hirsutum L.), que representa uma grande parcela da economia agrícola do país, os atuais níveis de problemas de sanidade, acumulados ao longo de alguns anos, podem ser considerados intoleráveis, não somente pelos efeitos que têm causado em termos de redução da produtividade, mas sobretudo por colocar em risco a sobrevivência da atividade agrícola considerada de uma maneira integrada.
A tecnologia de produção empregada nesta cultura tem sido uma das mais deficitárias e o aspecto de sanidade de sementes surge como o principal entrave na busca de uma qualidade melhor da produção. Patógenos associados às sementes, tais como Colletotrichum gossypii South. e $C$. gosssypii (South) var. cephalosporioides A. S. Costa, que são de difícil identificação ou distinção em relação a outras espécies saprófitas, requerem métodos mais detalhados visando sua identificação de um modo rápido e seguro em testes de sanidade.

Apesar da existência de métodos recomendados para análise em laboratório, a detecção desses organismos é inviável do ponto de vista de rotina, considerando não somente as dificuldades operacionais como também os fatores de reproducibilidade de resultados. A diagnose de tais patógenos em 
lotes de sementes é portanto uma necessidade indispensável que, ao lado de outras medidas culturais, genéticas e de manejo, representa uma medida de proteção de todo o sistema evitando perdas para a cultura do algodoeiro.

O uso de técnicas moleculares e marcadores bioquímicos, de proteínas e isoenzimas tem possibilitado o desenvolvimento de métodos rápidos, sensíveis e específicos no diagnóstico de patógenos de plantas, propiciando aos agricultores e produtores de sementes a garantia de um insumo de alta qualidade, livre de agentes causadores de doenças de importância epidêmica.

Os métodos de estudos das seqüências de DNA possibilitam uma análise mais precisa da variação genética pois podem detectar alterações mutacionais, em regiões codificadoras, de um número limitado de genes que se expressam em enzimas. Neste sentido pode-se citar entre outros, os trabalhos de Sreenivasaprasad et al. (1992, 1993, 1994); Correl et al. (1993); Crous et al. (1993); Sherriff et al. (1994); Vasconcelos et al. (1994); Sherriff et al. (1995); Vilarinhos (1995) e Vieira (1996). Grajal-Martin et al. (1993) conseguiram sucesso na identificação da raça 2 de Fusarium oxysporum f. sp. pisi de outras três raças. Guthrie et al.. (1993) também obtiveram sucesso trabalhando com Colletotrichum graminicola. Crowhurst et al.. (1991), trabalhando com duas raças de Fusarium solani f. sp. cucurbitae, também demonstraram a grande importância do uso de RAPD para fins de identificação.

Desta forma, o objetivo do presente trabalho foi o de utilizar marcadores moleculares de isoenzimas e proteínas; e de DNA, do tipo RAPD, para verificar a variabilidade genética em alguns isolados de C. gossypii e C. gossypii var. cephalosporioides.

\section{MATERIAL E MÉTODOS}

O presente trabalho foi desenvolvido no Laboratório de Biotecnologia de Sementes da UFLA. Nesta investigação foram empregados os isolados classificados por características morfológicas de colônia em: C. gossypii (P13, A26, Cg2) e C. gossypii var. cephalosporioides (P15, Cgc1, Cgc3, Cgc4, $\mathrm{Cgc5}, \mathrm{Cgc6}, \mathrm{A} 25)$. Parte dos isolados pertence a micoteca do Laboratório de Patologia de Sementes da UFLA e parte foi cedida pelo IAC.

Os isolados foram crescidos em meio BDA (batatadextrose-ágar), posteriormente repicados para meio líquido (Mills et al., 1994) e mantidos sob agitação no escuro, por sete dias. Após isto, o micélio de cada isolado foi filtrado à vácuo e recolhido em placa de Petri e liofilizado.

\section{Teste de Patogenicidade}

O inóculo foi obtido mediante o cultivo dos isolados em meio BDA por sete dias. A inoculação foi efetuada através da pulverização da suspensão de inóculo, na concentração de $10^{\circ}$ conídios $/ \mathrm{ml}$, em plantas da cultivar IAC 20 com 30 dias de idade, que foram mantidas em câmara úmida por $72 \mathrm{~h}$. Na testemunha foi empregada água deionizada esterilizada. As plantas foram isoladas umas das outras, com uma proteção plástica, evitando desta forma, contato entre plantas inoculadas com isolados diferentes.

As avaliações foram realizadas aos dez e 40 dias após a inoculação, segundo Tabela 1 de avaliação de severidade sugerida por Cia (1977), com adaptações, conforme abaixo apresentado.

\section{Extração e análise de proteínas totais dos isolados fúngicos}

Foram utilizados $50 \mathrm{mg}$ do micélio liofilizado aos quais foram adicionados $950 \mu \mathrm{l}$ do tampão de extração $(62,5 \mathrm{mM}$ Tris pH6,8; 2,3\% SDS; 5\% $\beta$ mercaptoetanol) acrescidos de $50 \mu \mathrm{l}$ de $\beta$-mercaptoetanol em microtubo do tipo eppendorf. Em seguida, os tubos foram agitados de $10 \mathrm{em} 10 \mathrm{~min}$ por 1 $\mathrm{h}$ à temperatura ambiente, centrifugados à $16.000 \mathrm{~g}$ por 10 min e o sobrenadante recolhido.

A avaliação da fração de proteína foi feita sob eletroforese SDS-PAGE a 12,5\% (gel separador) e 6\% (gel concentrador). Foram aplicados $30 \mu \mathrm{l}$ de mistura tampão da amostra (5 ml de glicerol; 2,5 ml de Tris- $\mathrm{HCl}, 0,62 \mathrm{M}, \mathrm{pH}$ 6,$8 ; 2,5 \mathrm{mg}$ de azul de bromofenol e completado o volume para $25 \mathrm{ml}$ com água) e extrato da proteína, na proporção 3:1. O sistema tampão gel/eletrodo utilizado foi Tris- glicina $+\mathrm{SDS} \mathrm{pH}=8,9$. As corridas eletroforéticas foram desenvolvidas a $12 \mathrm{~mA}$ no gel concentrador e $24 \mathrm{~mA}$ no gel separador. Após a corrida, os géis foram corados em solução Coomassie Brilliant Blue a 0,05\%, segundo Alfenas et al. (1991), durante $12 \mathrm{~h}$, e descorados em solução aquosa contendo etanol 5\% e ácido acético $10 \%$.

\section{Extração e análise de isoenzimas dos isolados fúngicos}

Para a análise isoenzimática foram colocados $15 \mathrm{mg}$ de micélio liofilizado em tubos eppendorf de $2 \mathrm{ml}$ e $200 \mu \mathrm{l}$ de tampão de extração (Tris- $\mathrm{HCl}$ 0,2M, $\mathrm{pH} 8,0, \beta$ mercaptoetanol $0,1 \%$, polivinilpirrolidone - PVP-40 0,4\%, polietilenoglicol -PEG 0,4\%, ácido etilenodiaminotetracético- EDTA $1 \mathrm{mM}$ ) foram adicionados. A mistura foi mantida a $4{ }^{\circ} \mathrm{C}$ por $24 \mathrm{~h}$, posteriormente centrifugada a $16.000 \mathrm{~g}$ por $30 \mathrm{~min}$ a $4^{\circ} \mathrm{C}$.

Foram aplicados $30 \mu \mathrm{l}$ do extrato protéico de cada amostra, nas cavidades dos géis de poliacrilamida a 4,5 e $7,5 \%$, sistema descontínuo. As isoenzimas foram separadas por eletroforese por aproximadamente $3 \mathrm{~h}$ a $4{ }^{\circ} \mathrm{C}$, a $150 \mathrm{~V}$ e foram reveladas para os sistemas esterase (EST), fosfatase ácida (ACP) e peroxidase (PO), segundo Alfenas et al. (1991). A avaliação foi feita com base na presença ou ausência de bandas.

\section{Extração e análise de DNA dos isolados fúngicos}

O DNA genômico foi extraído de $50 \mathrm{mg}$ de micélio liofilizado, previamente macerado com nitrogênio líquido, utilizando o protocolo de extração de Doyle \& Doyle (1987), modificado pela adição de $0,2 \%$ de $\beta$-mercaptoetanol.

As amostras tiveram a concentração de DNA determinada com o auxílio de um fluorímetro Hoefer Scientific Modelo TKO 100, onde foram empregadas alíquotas de $2 \mu \mathrm{l}$ de amostra para cada ml de tampão TNE 10X (1,3\% Tris- 
Variabilidade genética de isolados do complexo Colletotrichum associados a sementes...

base; 0,37\% Na2 EDTA.2 $\left.\mathrm{H}_{2} \mathrm{O} ; 11,68 \mathrm{NaCl} \mathrm{pH}=7,4\right)$.

A amplificação foi baseada em método descrito por Williams et al. (1990), usando dez primers de dez bases cada, da marca Operon Technologies (OPA4; OPA7; OPA17; OPA19; OPB1; OPD7; OPD17; OPE3; OPE13; OPF15), em tubos de $0,2 \mathrm{ml}$. A escolha dos primers se baseou em trabalho de Vieira (1996) com isolados pertencentes ao gênero Colletotrichum. A amplificação se deu em termociclador Perkin Elmer Modelo Gene Amp PCR System 2400. O programa de amplificação consistiu de temperatura inicial de $94{ }^{\circ} \mathrm{C}$ por 5 min, 45 ciclos de amplificação à $94{ }^{\circ} \mathrm{C}$ por 15 seg; $36{ }^{\circ} \mathrm{C}$ por $30 \mathrm{seg} ; 72{ }^{\circ} \mathrm{C}$ por $1 \mathrm{~min}$. Os produtos de amplificação do DNA foram separados em gel de agarose $1 \%$, submetidos a eletroforese em tampão TBE $(90 \mathrm{mM}$ Trisborato, $1 \mathrm{mM}$ EDTA, $\mathrm{pH} 8,0$ ), corados com brometo de etídio $(0,5 \mu \mathrm{g} / \mathrm{ml})$ e visualizados sob luz UV.

A avaliação foi realizada através da similaridade genética calculada pelo coeficiente de Jaccard (Rohlf, 1951) usando o programa NTSYS- pc 1.7.

\section{RESULTADOS E DISCUSSÃO}

Pelos resultados do teste de patogenicidade (Tabela 2), observa-se que os isolados $\mathrm{Cgc} 1, \mathrm{Cgc} 3, \mathrm{Cgc} 4, \mathrm{Cgc} 5, \mathrm{P} 15$, A25, A26 induziram sintomas típicos de ramulose, na forma de lesões foliares aos dez dias e superbrotamento aos 40 dias. Esses resultados não se apresentam totalmente similares aos da classificação inicial dos isolados, feita por características morfológicas de colônias. Assim é que o isolado A26, inicialmente classificado como C. gossypii, apresentou sintomas típicos de ramulose, ao passo que o isolado Cgc6 foi classificado como C. gossypii var. cephalosporioides, mas não apresentou sintomas típicos de ramulose por ocasião da inoculação. Essa classificação parcialmente diferenciada entre os métodos de características morfológicas das colônias e de patogenicidade em plantas pode ser devido a influência do tipo de resistência que envolve a relação patógeno-hospedeiro, uma vez que apenas a cultivar IAC-20 foi utilizada como hospedeiro. Este fato já foi comentado por Silva-Mann et al. (dados não publicados) em trabalho sobre identificação de resistência na interação patógeno-hospedeiro. Provavelmente

TABELA 1 - Escala de notas adaptada para avaliação dos sintomas em plantas de algodoeiro (Gossypium hirsutum) inoculadas com fungos do complexo Colletotrichum

\begin{tabular}{lc}
\hline \hline SINTOMA & NOTA \\
\hline $\begin{array}{l}\text { Planta sem sintoma (ausência de lesões) } \\
\text { Plantas com manchas estreladas nas folhas do } \\
\text { ponteiro }\end{array}$ & 2 \\
$\begin{array}{l}\text { Planta com redução dos internód ios no ponteiro e } \\
\text { com manchas foliares }\end{array}$ & 3 \\
$\begin{array}{l}\text { Planta com superbrotamento e pouca diminuição do } \\
\text { seu crescimento }\end{array}$ & 4 \\
$\begin{array}{l}\text { Planta com superbrotamento e com desenvolvimento } \\
\text { comprometido }\end{array}$ & 5 \\
\hline
\end{tabular}

a utilização de outras cultivares no teste de patogenicidade, poderia propiciar resultados diferenciados em relação ao comportamento patogênico dos referidos patógenos.

Com relação à análise eletroforética de proteínas totais, os padrões de bandas relativos aos diferentes isolados, mostraram-se extremamente semelhantes. Tal fato já era esperado, uma vez que o padrão de proteínas é bastante semelhante em espécies próximas (Alfenas et al., 1991).

Observa-se que a peroxidase (PO) diferenciou os fungos $\mathrm{Cg} 2, \mathrm{Cgc} 4$ e $\mathrm{A} 25$ dos demais e entre si. Os isolados Cgc4 e A25 (Figura 1), ambos agentes causais da ramulose, não apresentaram atividade para esta enzima. Vale ressaltar, no entanto, que essa enzima não foi eficiente, no presente estudo, em agrupar os isolados pertencentes ao complexo Colletotrichum.

Os isolados Cgc4, P15, A25 e A26 (C. gossypii var. cephalosporioides) apresentaram padrão de bandas para fosfatase ácida diferenciados em relação aos demais. Desta forma, apenas os isolados $\mathrm{Cgc5}$ e $\mathrm{Cgc} 3$, dentre os que apresentaram sintoma de ramulose por ocasião do teste de inoculação em plantas, não foram diferenciados dos isolados de $C$. gossypii por essa enzima. Já pelos padrões eletroforéticos da esterase, observa-se que os isolados Cgc1 e P15, ambos nota máxima pelo teste de patogenicidade em plantas, apresentaram padrões de bandas iguais entre si e diferente dos demais. Estes resultados discordam parcialmente dos encontrados por Vieira (1996), que menciona ser estes sistemas promissores para diferenciar estes organismos. No entanto, apesar de alguns isolados de C. gossypii var. cephalosporioides não terem sido separados dos de $C$. gossypii, é preciso que fique claro, que os isolados classificados

TABELA 2 - Resultados da avaliação de sintomas em teste de patogenicidade em algodoeiro (Gossypium hirsutum) cultivar IAC- 20, UFLA, Lavras, MG. 1997

\begin{tabular}{|c|c|c|}
\hline ISOLADO & SINTOMA & NOTA \\
\hline Cgc1 & $\begin{array}{l}\text { Planta com superbrotamento e com } \\
\text { desenvolvimento comprometido. }\end{array}$ & 5 \\
\hline $\mathrm{Cg} 2$ & $\begin{array}{l}\text { Planta sem sintoma (ausência de } \\
\text { lesões) }\end{array}$ & 1 \\
\hline $\mathrm{Cgc} 3$ & $\begin{array}{l}\text { Planta com superbrotamento e pouca } \\
\text { diminuição do seu crescimento. }\end{array}$ & 4 \\
\hline $\mathrm{Cgc} 4$ & $\begin{array}{l}\text { Planta com redução dos internódios no } \\
\text { ponteiro e com manchas foliares. }\end{array}$ & 3 \\
\hline Cgc5 & $\begin{array}{l}\text { Planta com superbrotamento e com } \\
\text { desenvolvimento comprometido. }\end{array}$ & 5 \\
\hline Cgc6 & $\begin{array}{l}\text { Plantas com manchas estreladas nas } \\
\text { folhas do ponteiro }\end{array}$ & 2 \\
\hline A 25 & $\begin{array}{l}\text { Planta com superbrotamento e com } \\
\text { desenvolvimento comprometido. }\end{array}$ & 5 \\
\hline A26 & $\begin{array}{l}\text { Planta com superbrotamento e pouca } \\
\text { diminuição do seu crescimento. }\end{array}$ & 4 \\
\hline P13 & $\begin{array}{l}\text { Planta sem sintoma (ausência de } \\
\text { lesões) }\end{array}$ & 1 \\
\hline P15 & $\begin{array}{l}\text { Planta com superbrotamento e com } \\
\text { desenvolvimento comprometido. }\end{array}$ & 5 \\
\hline
\end{tabular}




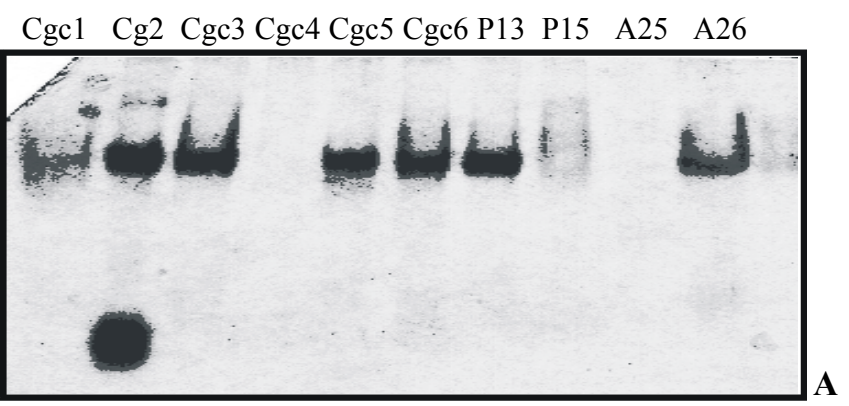

Cgc1 Cg2 Cgc3 Cgc4 Cgc5 Cgc6 P13 P15 A25 A26

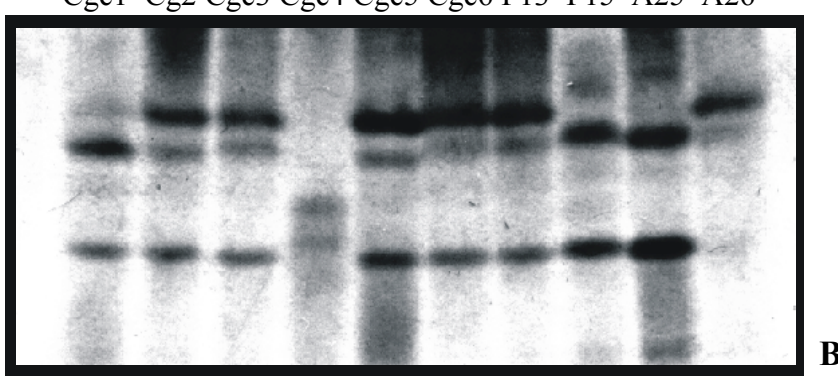

Cgc1 Cg2 Cgc3 Cgc4 Cgc5 Cgc6 P13 P15 A25 A26

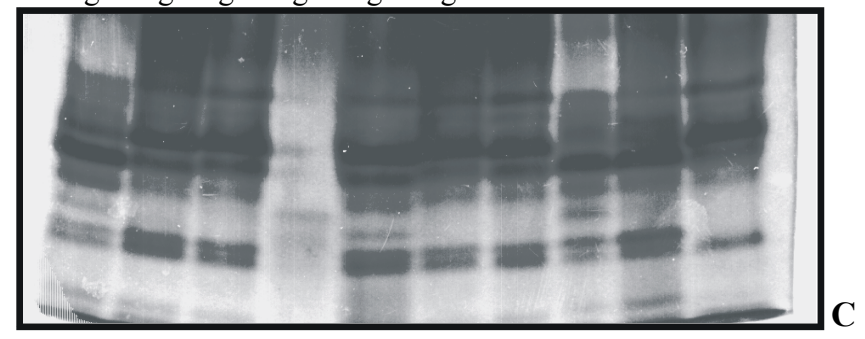

FIG. 1 - Padrões isoenzimáticos em géis de poliacrilamida, dos isolados de Colletotrichum gossypii e Colletotrichum gossypii var. cephalosporioides: Peroxidase (A), Fosfatase ácida (B), Esterase (C). C. gossypii: Cg2, P13, A26; C. gossypii var. cephalosporioides: Cgc1, Cgc3, Cgc4, Cgc5, Cgc6, P15, A25.

como C. gossypii, sempre apresentaram o mesmo padrão de bandas por esses sistemas. Desta forma, fica evidente a necessidade de se usar um maior número de sistemas para possibilitar separar aqueles isolados de C. gossypii var. cephalosporioides, não separados dos de C. gossypii pelos sistemas enzimáticos considerados neste estudo.

$\mathrm{Na}$ análise de RAPD, as reações de amplificação dos fragmentos de DNA geraram 41 bandas polimórficas e quatro monomórficas. A Figura 2 mostra um padrão de amplificação obtido com o primer OPF15. Os padrões de bandas de DNA, foram empregados para cálculo dos valores de similaridade genética, os quais mostraram similaridade mínima de $35 \%$ e máxima de $85 \%$. De acordo com a similaridade genética entre os pares de genótipos analisados (Tabela 3), os isolados $\mathrm{Cgc} 1$ e Cgc6; Cgc4 e P15 todos C. gossypii var. cephalosporioides, apresentaram maior similaridade (85\%), seguidos também dos isolados de C. gossypi var. cephalosporioides, $\mathrm{Cgc1}$ e $\mathrm{Cgc} 3$; $\mathrm{Cgc} 4$ e $\mathrm{Cgc} 5$; $\mathrm{Cgc1}$ e P15, com uma similaridade de

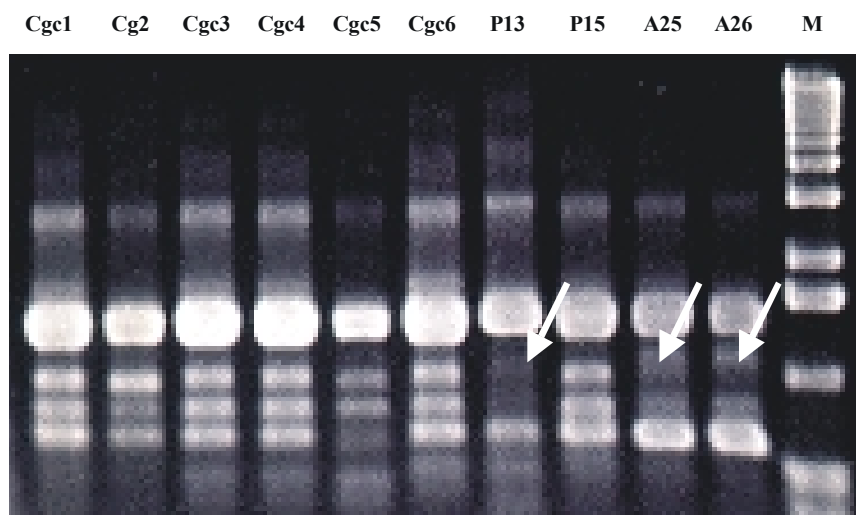

FIG. 2 - Análise eletroforética em gel de agarose mostrando produtos de amplificação do DNA de diferentes isolados de Colletotrichum gossypii e Colletotrichum gossypii var. cephalosporioides com o primer OPF15. Seta indica polimorfismo de bandas.

82,5\%. Estes resultados, com exceção do isolado Cgc6, estão de acordo com os obtidos em teste de patogenicidade onde os isolados $\mathrm{Cgc} 1, \mathrm{Cgc} 3, \mathrm{Cgc} 4, \mathrm{Cgc} 5, \mathrm{P} 15$ e A25 mostraram sintomas de ramulose, doença caracterizada por lesões foliares e superbrotamento. Torna-se importante ressaltar que apesar do isolado Cgc6 não ter apresentado sintomas típicos de ramulose, pelo teste de patogenicidade em plantas, este isolado foi classificado como C. gossypii var. cephalosporioides pelo teste de morfologia de colônia. $\mathrm{O}$ fato dele não ter apresentado sintomas típicos, pode ter sido, como já mencionado anteriormente, devido ao tipo de resistência que envolve a relação patógeno-hospedeiro. Desta forma, fica evidente a alta correlação entre os resultados de RAPD e os de caracterização morfológica de colônia. O isolado P13 (C. gossypii) se posicionou no dendrograma (Figura 3) em um grupo distante dos demais, apresentando uma similaridade de $60 \%$ com $\mathrm{Cg} 2$ (C. gossypii). No teste de patogenicidade ambos apresentaram sintomas de antracnose. Esta baixa similaridade entre os isolados de $C$. gossypii sugere que ocorre uma maior variação genética entre estes isolados do que entre os isolados de C. gossypii var. cephalosporioides. O isolado A26, classificado como $C$. gossypii por características morfológicas de colônia pelos resultados RAPD, apresentou-se numa faixa intermediária de similaridade em relação aos demais isolados, exibindo maiores porcentuais de similaridade com os isolados A25 e $\mathrm{Cgc3}$, ambos de C. gossypii var. cephalosporioides. Provavelmente, isso ocorreu em função das regiões amplificadas pelos primers anteriormente mencionados. Pelo teste de patogenicidade em plantas, este isolado apresentou sintomas de ramulose e o mesmo padrão de bandas da enzima fosfatase ácida que de outros isolados de C. gossypii var. cephalosporioides. A divergência genética entre C. gossypii e C. gossypii var. cephalosporioides foi de 48,3\%. Desta forma, estes resultados mostram que o uso de marcadores moleculares de DNA, pode ser de grande utilidade para a 
TABELA 3 - Estimativa de similaridades genéticas entre dez isolados de Colletrotrichum gossypii. gossypii e Colletrotrichum gossypii var. cephalosporioides, baseadas em dados de RAPD, pelo coeficiente de Jaccard. UFLA, Lavras, MG. 1999

\begin{tabular}{l|lllllllll}
\hline \hline & Cgc1 & Cg2 & Cgc3 & Cgc4 & Cgc5 & Cgc6 & P13 & P15 & A25 \\
\hline Cg2 & 0,675 & & & & & & & & \\
Cgc3 & 0,825 & 0,600 & & & & & & & \\
Cgc4 & 0,675 & 0,400 & 0,600 & & & & & & \\
Cgc5 & 0,650 & 0,475 & 0,625 & 0,825 & & & & & \\
Cgc6 & 0,850 & 0,625 & 0,775 & 0,725 & 0,700 & & & & \\
P13 & 0,375 & 0,600 & 0,350 & 0,350 & 0,425 & 0,375 & & & \\
P15 & 0,825 & 0,350 & 0,700 & 0,850 & 0,725 & 0,775 & 0,450 & & \\
A25 & 0,725 & 0,600 & 0,650 & 0,550 & 0,525 & 0,775 & 0,550 & 0,700 & \\
A26 & 0,625 & 0,650 & 0,750 & 0,450 & 0,525 & 0,675 & 0,500 & 0,550 & 0,700 \\
\hline
\end{tabular}

Isolados: $\mathrm{Cgc} 1, \mathrm{Cgc} 3, \mathrm{Cgc} 4, \mathrm{Cgc5}, \mathrm{Cgc} 6, \mathrm{P} 15, \mathrm{~A} 25$ (Colletotrichum gossypii var. cephalosporioides) e Cg2, P13, A26 (Colletrotrichum gossypii)

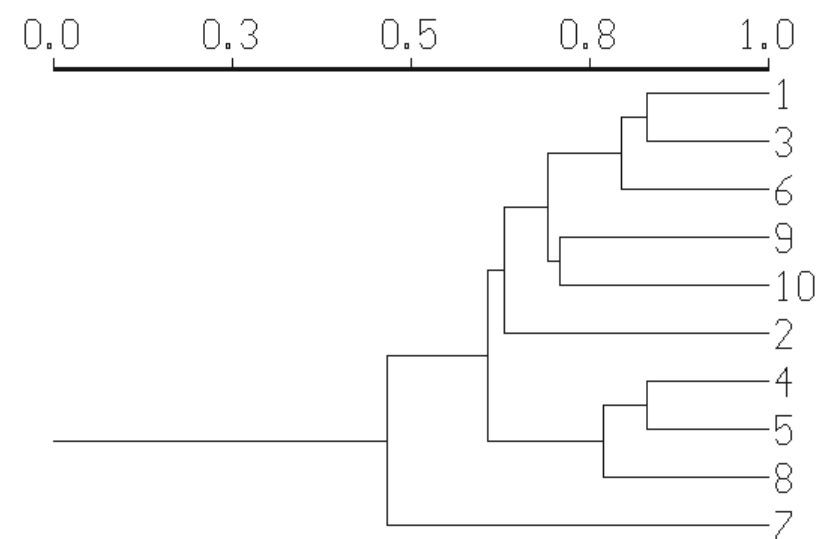

FIG. 3 - Dendrograma revelando a similaridade genética entre dez isolados de Colletrotrichum gossypii $e$ Colletotrichum gossypii var. cephalosporioides, baseado em coeficientes de similaridades Simple Matching, usando o método UPGMA.

Isolados: 1: Cgc1, 2: Cgc2, 3: Cgc3, 4: Cgc4, 5: Cgc5, 6: Cgc6 e 8: P15 - C. gossypii var. cephalosporioides; 7: P13, 9: A25 e 10: A26: $C$. gossypii.

identificação e diferenciação de importantes fungos fitopatogênicos, como já referido nos trabalhos de Sreenivasaprasad et al. (1992, 1993, 1994); Correl et al. (1993); Crous et al. (1993); Sherriff et al. (1994); Vasconcelos et al. (1994); Sherriff et al. (1995); Vilarinhos (1995); Vieira (1996).

\section{REFERÊNCIAS BIBLIOGRÁFICAS}

ALFENAS, A.C., PETERS, I., BRUNE, W. \& PASSADOR, G.C. Eletroforese de proteínas e isoenzimas de fungos de essências florestais. Viçosa: UFV. 1991.

CIA, E. Ocorrência e conhecimento das doenças de algodoeiro anual Gossypium hirsutum L. no Brasil. Summa Phytopathologia
3:167-193. 1977.

CORREL, J.C., RHOADS, D.D. \& GUEBER, J.C. Examination of mitocondrial DNA restriction fragment length polymorphims, DNA fingerprints and Randomly Amplified Polymorphic DNA of Colletotrichum orbiculare. Phitopathology 83:1199-1204. 1993.

CROUS, P.W., ALFENAS, A.C. \& WINGFIELD, M.J. Calonectria scoparia and Calonectria morginii sp. nov., and variation among isolates of their Cylindrocladium anamorphs. Micology Research 6:701-708. 1993.

CROWHURST, R.N., HAWTHORNE, B. T., RIKKERINK, E.H.A. \& TEMPLENTON, M.D. Diferentiation of Fusarium solani f. sp. crurcubitae. Current Genetics 20:391-396. 1991.

DOYLE, J.J., DOYLE, J.L. Isolation of plant DNA from fresh tissue. Focus 12:13-15. 1987.

GRAJAL-MARTIN, M.J., SIMON, C.J. \& MUEHLBAUER, F.J. Use of Random Amplified Polymorphic DNA (RAPD) to characterize race 2 of Fusarium oxysporum f.sp. pisi. Phytopatology 83:612-14. 1993.

GUTHRIE, P.A.I., MAGILL, W.W., REDERIKSEN, R.A. \& ODVODY, G.N. Random amplified polymorfic DNA markers: a system for identifying and differentiating isolates of Colletotrichum graminicola. Phytopathology 83:283-287. 1993.

MILLS, P.R., SREENIVASAPRASAD, S. \& BROWN, A.E. Detection fo the antracnose pathogen Colletotrichum. In: Schots, A., Dewey, F.M. \& Olver, R. (Eds.) Modern Assays for Plant Pathogenic Fungi: Identifcation, Detection na Qualication. Wallingford: Redwood Pres. 1994. pp.183-189.

ROHLF, F.J. Numerical Taxonomy and multivariate Analysis System. New York version v. 43, p.282-287, 1951

SREENIVASAPRASAD, S., BROWN, A.E. \& MILLS, P.R. Coffee berry disease pathogen in Africa: genetic structure and relationship to the group species Colletotrichum gloesporioides. Micology Research 8:995-1000. 1993.

SREENIVASAPRASAD, S., BROWN, A.E. \& MILLS, P.R. DNA sequence variation and iterrelationships among Colletotrichum species causing strawberry anthracnose. Physiological and Molecular Plant Pathology 41:265-281. 1992.

SREENIVASAPRASAD, S., BROWN, A.E. \& MILLS, P.R. Nucleotide sequence of the rDNA spacer 1 enables identification of isolates of Colletotrichum as c. acutatum. Mycology Research 98:186-188. 1994.

SHERRIFF, C., WHELAN, M.J., ARNOLD, G.M. \& BAILEY, J.A. rDNA sequence analysis confirms the distinction between Colletotrichum graminicola and C. sublineolum. Mycology Research 99:475-478. 1995.

SHERRIFF, C., WHELAN, M.J., ARNOLD, G.M., LAFAY, J.F., BRYGOO,Y. \& BAILEY, J.A. Ribosomal DNA sequence analysis revals new species groupings in the genus Colletotrichum. Experimental mycology 18:121-138. 1994.

VASCONCELOS, M.J.V., MACHADO, M.A., ALMEIDA, A.M.R., HENNING, A.A., BARROS, E.G. \& MOREIRA, M.A. Differentiation of Colletotrichum truncatum isolates by Random Amplified Polymorfic DNA. Fitopalologia brasileira 19:520-523. 1994.

VIEIRA, M.G.G.C. Utilização de marcadores moleculares no monitoramento da qualidade sanitária e nível de deterioração de sementes de algodoeiro. (Tese - Doutorado). Universidade Federal de Lavras. Lavras. 1996. 


\section{R. Silva-Mann et al.}

VILARINHOS, A.D., PAULA JR, T.J., BARROS, E.G., MOREIRA, M.A. \& Characterization of races of Colletotrichum lindermuthianum by the random amplified polymorphic DNA technique. Fitopatologia Brasileira 20:194-198. 1995.
WILLIAMS, J.G.K., KUBELIK, A.R., LIVAK, K.J., RAFALSKI, J.A. \& TINGEX, S.V. DNA polymorphism and amplified by arbitrary primers are useful as genetic markers. Nucleic Acid Research 18:6531-6535. 1990. 